\title{
Evapotranspiração e coeficiente de cultivo de cafeeiros adultos
}

\author{
Bruno Patias Lena(1), Danilton Luiz Flumignan ${ }^{(1)}$ e Rogério Teixeira de Faria(2) \\ (1)Universidade de São Paulo, Escola Superior de Agricultura Luiz de Queiroz, Departamento de Engenharia de Biossistemas, Avenida \\ Pádua Dias, no 11, Caixa Postal 9, CEP 13418-900 Piracicaba, SP. E-mail: brunoplena@usp.br; flumigna@esalq.usp.br ${ }^{(2)}$ Instituto Agronômico \\ do Paraná, Área de Engenharia Agrícola, Rodovia Celso Garcia Cid, PR 445 Km 375, Caixa Postal 481, CEP 86001-970 Londrina, PR. \\ E-mail: rtfaria@iapar.br
}

\begin{abstract}
Resumo - O objetivo deste trabalho foi determinar a evapotranspiração (ET) de cafeeiros adultos, irrigados por aspersão e gotejamento, e não irrigados, bem como os coeficientes de cultivo $(\mathrm{Kc})$ de cafeeiros sob os dois regimes hídricos. O experimento foi realizado em Londrina, PR, com cafeeiros da cultivar Iapar 59, com cinco e seis anos de idade, de setembro de 2006 a agosto de 2008. A evapotranspiração foi medida por cinco lisímetros de pesagem, dos quais dois irrigados por aspersão, um por gotejamento e os outros dois sem irrigação. A irrigação foi aplicada, em média, duas vezes por semana, para manter o solo com umidade próxima à de capacidade de campo. O coeficiente de cultivo foi determinado pela razão entre a ET das plantas dos tratamentos irrigados e a evapotranspiração de referência (ETo). Os cafeeiros adultos apresentaram valor médio de ET mais elevado no tratamento irrigado por aspersão $\left(3,2 \mathrm{~mm} \mathrm{dia}^{-1}\right)$, em comparação aos de outros tratamentos, que apresentaram médias equivalentes entre si $\left(2,8 \mathrm{~mm} \mathrm{dia}^{-1}\right)$. A mesma tendência foi observada para $\mathrm{Kc}$, em razão da relação ET e ETo, com valor médio maior para o tratamento irrigado por aspersão (1) e menor para o gotejamento $(0,88)$.
\end{abstract}

Termos para indexação: Coffea arabica, demanda hídrica, lisímetros, irrigação.

\section{Evapotranspiration and crop coefficient of adult coffee trees}

\begin{abstract}
The objective of this work was to determine the evapotranspiration (ET) of adult coffee trees irrigated by sprinkler and drip and under no irrigation, as well as the crop coefficient $(\mathrm{Kc})$ under both water regimes. The experiment was performed in Londrina, PR, Brazil, with the coffee cultivar Iapar 59, from September 2006 to August 2008, with five and six-year-old plants. Evapotranspiration was measured by five weighting lysimeters, two of which were under sprinkler irrigation, one under drip system and two others without irrigation. Irrigation was applied twice a week to maintain soil moisture near field capacity. The crop coefficient was determined by the ratio between ET of the irrigated plants and the reference crop evapotranspiration (ETo). A higher ET mean was found for coffee plants under sprinkler irrigation $\left(3.2 \mathrm{~mm} \mathrm{day}^{-1}\right)$, in comparison to the ones under the other treatments, which showed similar means $\left(2.8 \mathrm{~mm} \mathrm{day}^{-1}\right)$. Kc values followed the same trend of ET, due to the ET and ETo ratios, with a higher mean for sprinkler irrigation (1), followed by drip irrigation (0.88).
\end{abstract}

Index terms: Coffea arabica, water demand, lysimeters, irrigation.

\section{Introdução}

A quantificação do consumo hídrico pelas plantas é importante em diversas áreas da agricultura, tais como estudos de demanda e manejo de irrigação, zoneamento agrícola, estimativa de produção e estudos hidrológicos em geral. A evapotranspiração (ET) está diretamente relacionada a tais estudos e é definida como a quantidade de água consumida por uma determinada cultura. Segundo Allen et al. (1998), ET é a combinação da evaporação (E), que é proveniente do solo, e a transpiração $(\mathrm{T})$, relacionada à planta.

Com o desenvolvimento de uma cultura, as taxas de $\mathrm{E}$ e $\mathrm{T}$ variam consideravelmente, em consequência da área foliar (Allen et al., 1998). Na fase inicial, E representa a maior parte do fluxo de ET, uma vez que o solo encontra-se exposto quase por completo às variações atmosféricas, em razão da pequena área foliar da cultura. Na fase da floração ao início de enchimento de grãos, graças à grande área foliar, as taxas de $\mathrm{T}$ são mais altas que as de E. Nas fases seguintes, E volta a aumentar e $\mathrm{T}$ a diminuir, pela senescência da cultura.

Os fatores que mais influenciam $\mathrm{E}$ e $\mathrm{T}$, portanto ET, são as condições atmosféricas locais, tais como temperatura, radiação solar, umidade relativa do ar e vento. Fatores relacionados ao manejo da cultura também influenciam as taxas de ET, tais como cultivar, população de plantas, irrigação e controle de pragas.

Pesq. agropec. bras., Brasília, v.46, n.8, p.905-911, ago. 2011 
Finalmente, também afetam ET as características de solo relacionadas à fertilidade, cor e capacidade de retenção de água (Allen et al., 1998).

A medição de ET é feita por várias métodos, com destaque para os métodos de balanço de energia, balanço de água no solo e lisimetria de pesagem. Além desses, há os métodos de estimativa a partir de dados meteorológicos e o tanque de evaporação (Allen et al., 1998). A medição de ET com lisímetros de pesagem é o método mais preciso, além de ser possível determinar ET em espaço de tempo variável, em intervalos de 10 min ou menos (Howell et al., 1985; Faria et al., 2006; Carvalho et al., 2007).

Além do consumo de água da cultura de interesse, define-se também a evapotranspiração de referência (ETo). Segundo Allen et al. (1998), essa corresponde à demanda hídrica de uma superfície padronizada, de uma vegetação hipotética similar à grama, caracterizada por crescimento vegetativo vigoroso, mantida sem deficiência hídrica, com resistência aerodinâmica de $70 \mathrm{~s} \mathrm{~m}^{-1}$, altura permanente de $12 \mathrm{~cm}$ e albedo de 0,23 . O método de Penman-Monteith é considerado o padrão para a determinação da ETo, (Allen, 1986; Smith et al., 1991; Allen et al., 1998), a qual é estimada a partir de dados de radiação, temperatura do ar, umidade relativa e velocidade do vento.

Por meio da razão entre ET da cultura de interesse e ETo, determina-se o coeficiente de cultivo (Kc), que representa a integração dos diferentes efeitos que fazem com que a cultura de interesse apresente comportamento diferente da cultura de referência. Segundo Lascano \& Sojka (2007), o Kc é requerido nas fases de dimensionamento e manejo da irrigação.

O objetivo deste trabalho foi determinar a evapotranspiração (ET) de cafeeiros adultos, irrigados por aspersão e gotejamento, e não irrigados, bem como os coeficientes de cultivo $(\mathrm{Kc})$ de cafeeiros sob os dois regimes hídricos.

\section{Material e Métodos}

O estudo foi realizado de 1/9/2006 a 31/8/2008, no Instituto Agronômico do Paraná (Iapar), em Londrina, $\mathrm{PR}$, a $23^{\circ} 18^{\prime} \mathrm{S}, 51^{\circ} 09^{\prime} \mathrm{W}$, à altitude de $585 \mathrm{~m}$. A região é de clima subtropical úmido (Cfa), conforme Köppen, com temperatura média anual de $21^{\circ} \mathrm{C}$ e precipitação acumulada de $1.584 \mathrm{~mm}$ anuais (Iapar, 2009). O solo da área experimental é classificado como Latossolo Vermelho eutroférrico (Santos et al., 2006).
$\mathrm{Na}$ área experimental, foram instalados cinco lisímetros de pesagem construídos com caixa dupla, das quais a externa era de concreto e a interna de aço carbono, com dimensões internas de 1,9 m de comprimento, 1,4 m de largura e 1,3 $\mathrm{m}$ de profundidade. A caixa de aço foi colocada sobre uma balança, com sistema de redução de massa de aproximadamente 45 vezes acoplado a uma célula de carga, cujo sinal era enviado para um sistema de aquisição e armazenamento de dados (datalogger). Sob a caixa interna, foi acoplado um reservatório de drenagem de água, constituído de PVC, no qual o excesso de água ficava armazenado e era, então, contabilizado pelo sistema de pesagem até a abertura dos registros. Semanalmente, os dados coletados eram descarregados em um módulo de memória, por meio de uma interface digital, e transferidos ao computador para serem analisados. As calibrações dos lisímetros foram realizadas previamente, conforme descrito em Faria et al. (2006).

Em outubro de 2002, foram transplantadas duas mudas de cafeeiro (Coffea arabica L.), da cultivar Iapar 59, em uma cova dentro de cada lisímetro e na área externa. As covas estavam espaçadas de 1,6 m na linha e $2 \mathrm{~m}$ entre linhas (Figura 1). As plantas irrigadas por aspersão foram, desde o seu transplantio, manejadas com este sistema. O mesmo fato ocorreu com as plantas sem irrigação. Porém, a irrigação por gotejamento foi estabelecida apenas no início do segundo ano de cultivo; até essa época, a condução era realizada sem irrigação. Por fim, as plantas da área externa também foram conduzidas sem irrigação. Assim, a partir do quinto e sexto anos após o transplantio, foram avaliados os seguintes sistemas de irrigação: irrigação por aspersão, em dois lisímetros; irrigação por gotejamento, em um lisímetro; e não irrigado, em dois lisímetros.

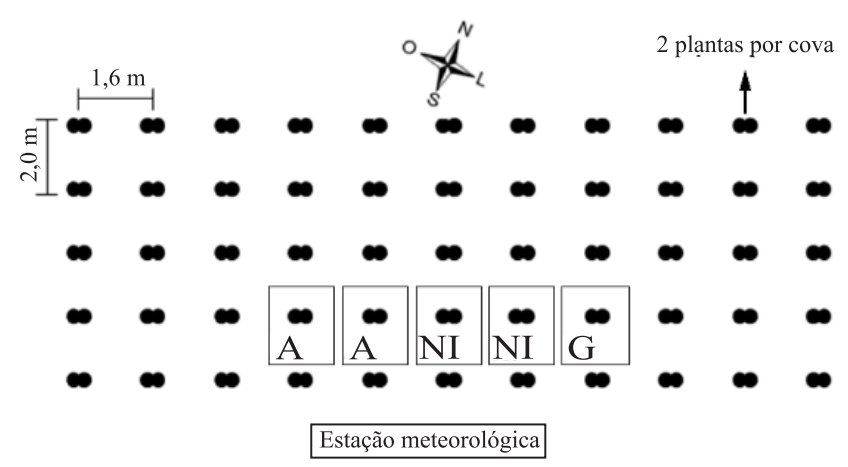

Figura 1. Croqui da área experimental: cafeeiro irrigado por aspersão (A), não irrigado (NI) e irrigado por gotejamento (G). 
A irrigação foi aplicada com frequência média de duas vezes por semana, para manter o solo com umidade próxima à da capacidade de campo (CC). A CC foi determinada em campo nos lisímetros, após descontar a drenagem e a evaporação, ao final de quatro dias após a ocorrência de chuva suficiente para saturar o solo, conforme Bernardo et al. (2005). Assim, atribuiu-se à condição de CC a lâmina de $150 \mathrm{~mm}$. $\mathrm{O}$ armazenamento de água no solo, no ponto de murcha permanente (PMP), foi obtido a partir da caracterização física do solo do local (Faria \& Caramori, 1986), que mostrou valor de água disponível igual a $10 \%$, com umidade em base de volume. Portanto, para a profundidade de 1,3 $\mathrm{m}$ do lisímetro utilizado, o valor de capacidade de água disponível (CAD) foi igual a $130 \mathrm{~mm}$, e o armazenamento no PMP igual à massa do lisímetro à $\mathrm{CC}$, descontados $130 \mathrm{~mm}$, portanto, $20 \mathrm{~mm}$. A irrigação por aspersão foi realizada com um regador de mão, com capacidade de aproximadamente $15 \mathrm{~L}$, e a água foi despejada diretamente em todo o solo do lisímetro. $\mathrm{Na}$ irrigação por gotejamento, foi utilizado um galão de plástico que servia como reservatório e, depois de colocada a água no galão, era conduzida por uma mangueira até a base da planta, onde um tubo perfurado fazia a aplicação de água concentrada na área sombreada da copa.

Estimou-se a ET diária pelo balanço de entrada e saída de água no sistema, conforme a equação:

$$
\mathrm{ET}=\mathrm{P}+\mathrm{I} \pm \mathrm{ES}-\mathrm{D} \pm \Delta \mathrm{A},
$$

em que: (I), irrigação; (P), precipitação; (D), drenagem; (ES), escoamento superficial, considerado zero, em razão da borda elevada dos lisímetros; e $(\Delta \mathrm{A})$, diferença de armazenamento, todos expressos em milímetros. Os valores de $\mathrm{Kc}$ foram determinados nos sistemas irrigados, conforme Doorenbos \& Kassam (1979), por $\mathrm{Kc}=\mathrm{ET} / \mathrm{ETo}$, em que: ET é a evapotranspiração da cultura $\left(\mathrm{mm} \mathrm{dia}^{-1}\right)$; e ETo é a evapotranspiração de referência $\left(\mathrm{mm} \mathrm{dia}^{-1}\right)$.

Os valores de ETo foram determinados na escala diária, pelo programa Clima (Faria et al., 2002). Os dados meteorológicos requeridos para estimar os valores de ETo (temperatura e umidade do ar, radiação solar e velocidade do vento) foram obtidos na Estação Meteorológica, do Instituto Tecnológico Simepar, localizada ao lado da área experimental (Figura 1).

Foram determinados os valores de índice de área foliar (IAF) a cada bimestre, e os dados foram utilizados como parâmetros para a análise do crescimento dos cafeeiros. Para isso, foi realizada a contagem do número de ramos plagiotrópicos das duas plantas do lisímetro, bem como o número de folhas de nove ramos, amostrados em cada terço das plantas, dos quais três ramos no inferior, três no médio e três no superior. Determinou-se, ainda, sem destacar, o comprimento (C) e largura (L) de 30 folhas - dez para cada terço das plantas.

$\mathrm{O}$ IAF foi obtido por IAF $=\mathrm{ATF} / \mathrm{AT}$, em que: ATF é a área total de folhas $\left(\mathrm{m}^{2}\right)$; e AT é a área do terreno disponível para as plantas $\left(2,66 \mathrm{~m}^{2}\right)$. Da contagem do número de folhas de cada ramo amostrado, foi calculada a média, e esse valor representou a quantidade média de folhas em cada ramo plagiotrópico (FRP). A área de cada folha (AF) foi obtida pela equação, ajustada por Flumignan et al. (2008), AF =0,6751(C $\times$ L), em que: C é o comprimento $(\mathrm{cm})$; e L é a largura da folha $(\mathrm{cm})$. Assim, a média da área das 30 folhas representou a área foliar média (AFM). Realizou-se a contagem do número de ramos plagiotrópicos em cada uma das duas plantas da cova, e a sua soma representou o total de ramos plagiotrópicos (TRP). Finalmente, a ATF foi obtida por, $\mathrm{ATF}=\mathrm{FRP} \times \mathrm{AFM} \times \mathrm{TRP} / 2$. $\mathrm{O}$ divisor 2 foi utilizado, pois, no caso de duas plantas adultas cultivadas na mesma cova, somente metade dos ramos emitem folhas, pois eles têm acesso direto a luz solar. Por outro lado, os ramos que são emitidos para dentro do dossel não apresentam folhas.

\section{Resultados e Discussão}

Os sistemas irrigados foram mantidos com armazenamento de água no solo próximo à condição de $\mathrm{CC}$, durante todo o período experimental (Figura 2 B). Porém, no sistema sem irrigação, durante alguns períodos secos, o armazenamento de água no solo situou-se próximo, ou até mesmo abaixo, do nível de PMP (setembro de 2006 a janeiro de 2007, e maio a dezembro de 2007). Para evitar a morte das plantas pelo deficit hídrico severo, foi aplicada uma lâmina de $30 \mathrm{~mm}$ às plantas não irrigadas, nos dias 15/9/2006, 25/11/2006 e 15/7/2007.

Em todos os sistemas, o crescimento da área foliar variou em razão da época do ano (Figura $2 \mathrm{~A}$ ), pelas características fisiológicas do cafeeiro (Camargo \& Camargo, 2001). Em geral, observou-se que o IAF comportou-se da mesma forma, em todos os tratamentos, 
ao longo do tempo. Assim, de novembro a dezembro de 2006, as plantas apresentaram IAF próximo de 12 , o qual decresceu acentuadamente durante o outono e inverno até atingir valores ao redor de três, em meados de novembro de 2007. Comportamento semelhante ocorreu no ano seguinte, em que o IAF, no verão, aumentou rapidamente até próximo de 10 e, depois, diminuiu a valores próximos de quatro em agosto de 2008.

Os valores de IAF foram diferentes entre os três sistemas de irrigação avaliados no quinto e semelhantes no sexto ano de cultivo. Isso se deve ao fato de que o quinto ano foi de alta produção, com 80,80 e 30 sacas ha $^{-1}$ de café beneficiado, para os cafeeiros sob aspersão, gotejamento e não irrigado, respectivamente, e o sexto ano foi de baixa produção, com 4, 2 e 12 sacas $\mathrm{ha}^{-1}$ de café beneficiado para os mesmos sistemas. Assim, no quinto ano, o IAF foi menor nas plantas irrigadas, possivelmente pelo fato de
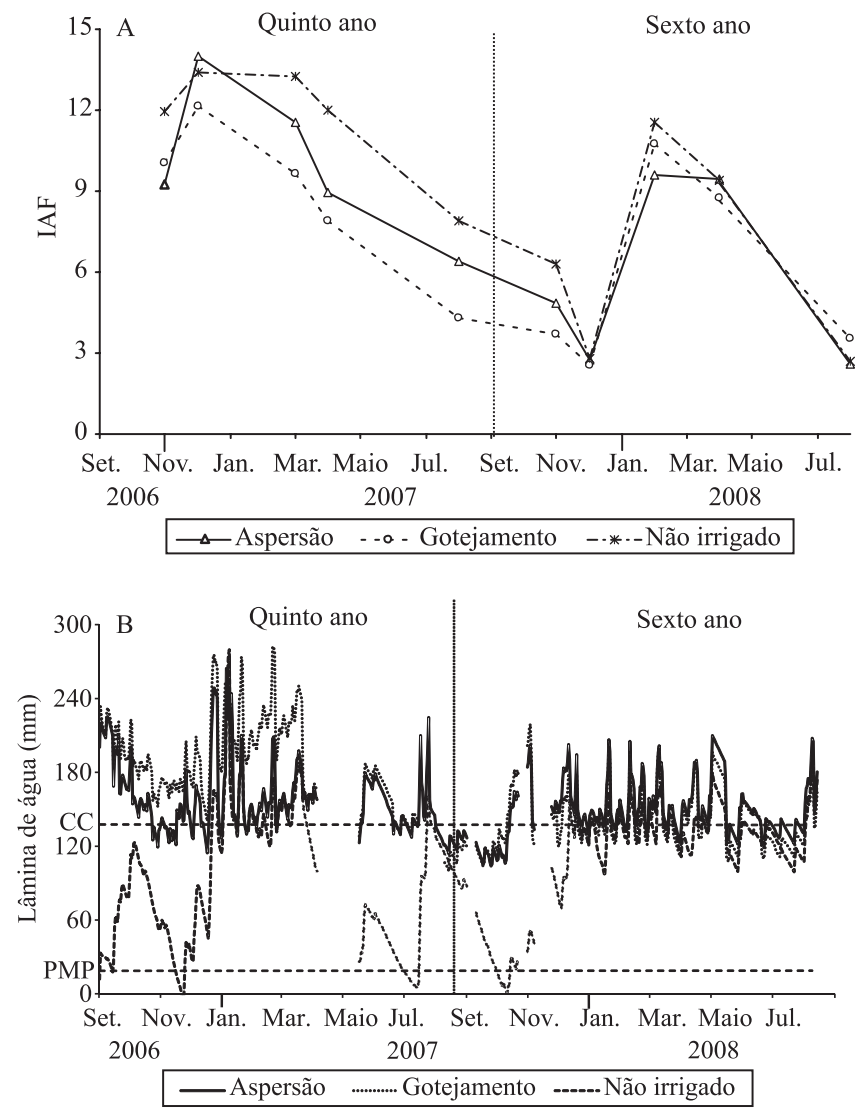

Figura 2. Índice de área foliar (IAF) dos cafeeiros (A) e armazenamento de água no solo (B), dos sistemas irrigados por aspersão, gotejamento e não irrigado, em Londrina, PR, 2006-2008. CC, capacidade de campo; PMP, ponto de murcha permanente. a maior parte dos fotoassimilados ter sido direcionada para sustentar a alta produtividade, ao invés de estimular o crescimento de folhas e ramos. Nas plantas não irrigadas, em razão da limitação hídrica observada naquele ano, a produção de frutos foi menor, e o uso da água predominou como dreno dos fotoassimilados, para a manutenção e crescimento do dossel vegetativo, como estratégia de sobrevivência. Assim, o índice de colheita - razão entre a produtividade de grãos e a produção total de biomassa seca - foi maior para as plantas irrigadas e menor para as não irrigadas, o que corrobora os dados de Floss (2006). No entanto, no sexto ano, não foram observadas tais diferenças nos valores de IAF, em razão da baixa produtividade característica da bienalidade dos cafeeiros (Camargo \& Camargo, 2001). Nesse ano, a área foliar disponível foi suficiente para produzir os fotoassimilados necessários para sustentar a baixa produtividade das plantas, em todos os sistemas, e a maior parte dos fotoassimilados deve ter sido utilizada para o crescimento dos ramos das plantas.

Outra constatação importante refere-se à duração das folhas no quinto ano. Enquanto as plantas irrigadas começaram a perder suas folhas por volta de dezembro de 2006, as não irrigadas somente começaram a perder suas folhas três meses depois, em março de 2007. Segundo Floss (2006), essa característica das plantas submetidas a estresse hídrico contribui para o aumento da produtividade das culturas, pois permite a manutenção da assimilação foliar e aumenta a duração da fase de enchimento de grãos, tal qual observado por Gomes et al. (2000).

Nos três sistemas, os maiores valores de ET foram registrados de setembro a abril, e os menores de maio a agosto, seguindo a variação de ETo durante o período analisado (Figura 3). As taxas de ET foram mais elevadas na irrigação sob aspersão e menores na irrigação sob gotejamento e não irrigado (Figura 3 A, Tabela 1). Essas diferenças são atribuídas à relação direta entre a evaporação e a umidade na camada superficial do solo, que foi maior na irrigação por aspersão, assim como observado por Flumignan \& Faria (2009) e Flumignan et al. (2011). Apesar de também haver molhamento quando as plantas foram irrigadas por gotejamento, a aplicação da água foi localizada sob a copa, região completamente sombreada pelas folhas, o que pode explicar as taxas de ET, na irrigação por gotejamento, bastante próximas das encontradas no não irrigado. Essa constatação também foi feita por Flumignan 
et al. (2011), ao avaliar cafeeiros adultos (três e quatro anos de idade). Todavia, esses dados diferem dos encontrados por Flumignan \& Faria (2009), pois, no trabalho desses autores, as plantas encontravam-se na fase de formação (um e dois anos de idade) e, portanto, com pouca área foliar.

As médias anuais de ETo foram similares nos dois anos do experimento (em torno de 3,2 a 3,3 $\mathrm{mm} \mathrm{dia}^{-1}$ ), enquanto as médias de ET foram cerca de 33\% mais elevadas no quinto ano, em comparação ao sexto ano, para os dois sistemas irrigados, e $20 \%$ mais elevadas no não irrigado (Tabela 1). O decréscimo de ET no sexto ano pode ter ocorrido em razão da redução da área foliar (Figura $2 \mathrm{~A}$ ), e também pode ser explicado pela baixa produtividade das plantas nesse ano. Durante todo o período experimental, as médias de ET foram similares na irrigação por gotejamento e no não irrigado (em torno de 2,8 $\mathrm{mm} \mathrm{dia}^{-1}$ ) e foram suplantadas, em cerca de $14 \%$, pela média do irrigado sob aspersão $\left(3,17 \mathrm{~mm} \mathrm{dia}^{-1}\right)$. Maiores médias de ET ocorreram no
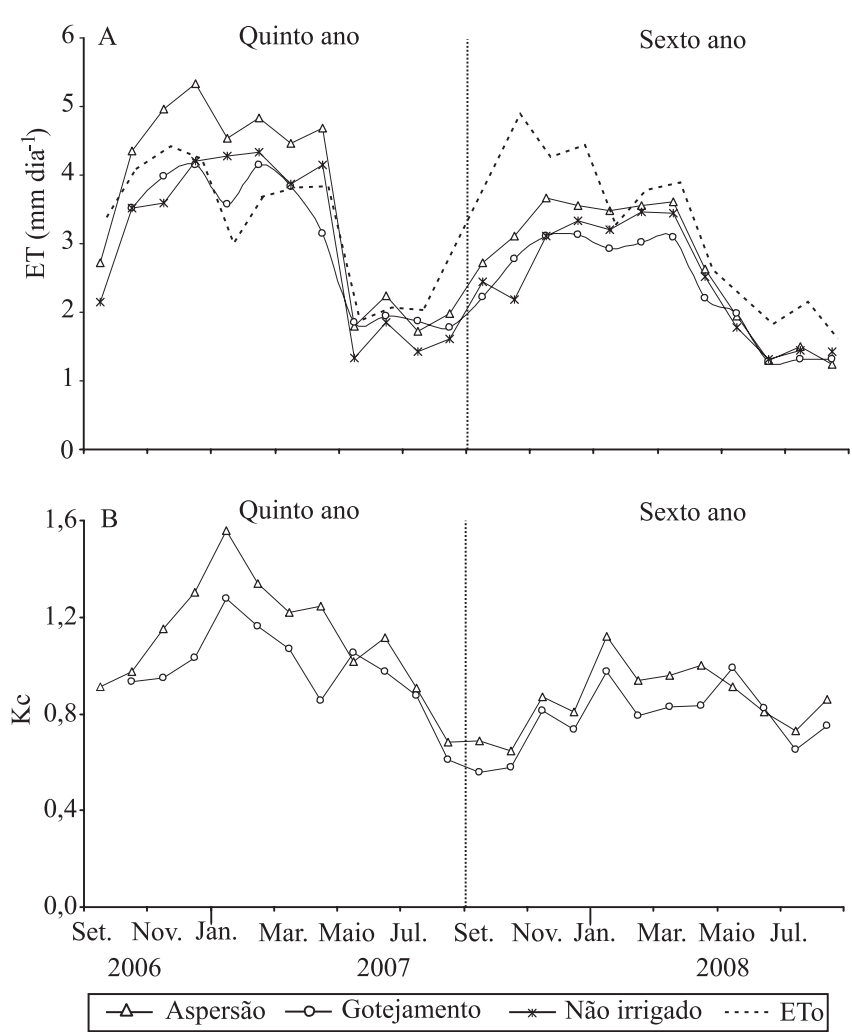

Figura 3. Média mensal de evapotranspiração (ET), nos cafeeiros irrigados por aspersão, gotejamento e não irrigado, e evapotranspiração de referência (ETo) (A); e coeficiente de cultivo $(\mathrm{Kc})$ para os cafeeiros irrigados por aspersão e gotejamento (B), em 2006-2008. verão, seguidas de médias intermediárias na primavera e outono e menores no inverno (Tabela 1). A variação estacional de ET pode ser atribuída não somente à sua relação direta com a ETo, mas também ao IAF, que também a afeta diretamente e oscila ao longo do ano, conforme apresentado na Figura $2 \mathrm{~A}$.

Os valores de Kc também foram mais elevados no quinto ano e reduzidos no sexto. Isso ocorreu em razão dos valores constantes de ETo, nos dois anos, e das taxas mais elevadas de ET no quinto ano e menores no sexto (Figura 3, Tabela 1). Os valores médios de Kc, durante os dois anos, foram maiores para o irrigado por aspersão $(1,00)$ e menores para o irrigado por gotejamento $(0,88)$. Menores médias de Kc ocorreram na primavera e inverno, em razão do menor IAF, comparadas aos valores mais altos obtidos no verão e outono, quando o dossel encontrava-se com área foliar bastante desenvolvida. Essa constatação também foi obtida por Flumignan \& Faria (2009) em cafeeiros com dois anos de idade.

Villa Nova et al. (2002) estimaram Kc de 1,036, para cafeeiros irrigados por aspersão convencional, em Piracicaba, SP, com 40 meses de idade, próximo ao encontrado para o cafeeiro irrigado por aspersão, na média dos dois anos analisados $(0,99)$, no presente trabalho.

Ao utilizar tensiômetros, para determinar o armazenamento de água no solo, Oliveira et al. (2003) encontraram $\mathrm{Kc}$ igual a 0,96, durante quatro meses de avaliação de cafeeiros da cultivar Catuaí IAC 44, aos 16 anos de idade, irrigados por gotejamento, na

Tabela 1. Evapotranspiração de referência (ETo), evapotranspiração (ET) e coeficientes de cultivo (Kc) de cafeeiros irrigados por aspersão (A), gotejamento $(\mathrm{G})$ e não irrigados (NI), durante estações do ano agrícola em 2006/2007 e 2007/2008.

\begin{tabular}{|c|c|c|c|c|c|c|c|}
\hline \multirow[t]{2}{*}{ Ano agrícola } & \multirow{2}{*}{ Estação } & \multirow{2}{*}{$\begin{array}{c}\text { ETo } \\
\left(\mathrm{mm} \mathrm{dia}{ }^{-1}\right)\end{array}$} & \multicolumn{3}{|c|}{ ET $\left(\mathrm{mm} \mathrm{dia}{ }^{-1}\right)$} & \multicolumn{2}{|c|}{$\mathrm{Kc}$} \\
\hline & & & $\mathrm{A}$ & $\mathrm{G}$ & NI & $\mathrm{A}$ & G \\
\hline \multirow{4}{*}{$\begin{array}{l}2006 / 2007 \\
\text { (5o ano) }\end{array}$} & Primavera & 3,95 & 3,96 & 3,76 & 3,11 & 1,03 & 0,94 \\
\hline & Verão & 3,60 & 4,90 & 3,98 & 4,27 & 1,40 & 1,15 \\
\hline & Outono & 3,44 & 4,02 & 3,43 & 3,47 & 1,19 & 1,05 \\
\hline & Inverno & 2,35 & 1,97 & 1,88 & 1,63 & 0,90 & 0,84 \\
\hline Média & & 3,30 & 3,60 & 3,23 & 3,03 & 1,12 & 1,00 \\
\hline \multirow{4}{*}{$\begin{array}{l}2007 / 2008 \\
\text { (6o ano) }\end{array}$} & Primavera & 4,39 & 3,09 & 2,63 & 2,51 & 0,72 & 0,62 \\
\hline & Verão & 3,78 & 3,53 & 3,02 & 3,33 & 0,96 & 0,84 \\
\hline & Outono & 3,02 & 2,86 & 2,50 & 2,73 & 0,96 & 0,87 \\
\hline & Inverno & 1,89 & 1,38 & 1,30 & 1,38 & 0,78 & 0,74 \\
\hline Média & & 3,22 & 2,73 & 2,40 & 2,53 & 0,87 & 0,78 \\
\hline Média geral & & 3,26 & 3,17 & 2,77 & 2,79 & 0,99 & 0,88 \\
\hline
\end{tabular}


região de Lavras, MG. Apesar de se tratar de cafeeiros adultos, o tempo de avaliação desse estudo limita o uso do Kc recomendado, pois, como demonstrado no presente trabalho, o Kc é bastante variável ao longo do ano de cultivo. Ainda assim, o valor encontrado por esses autores está em conformidade com as médias encontradas no presente trabalho.

Sato et al. (2007) trabalharam com a cultivar IAC 44, irrigada por gotejamento, na região de Lavras, $\mathrm{MG}$, e encontraram $\mathrm{Kc}$ de 0,59 e 1,16, durante o outono e o inverno de 2004, quatro anos após as plantas terem sido recepadas. Oliveira et al. (2007) também utilizaram irrigação por gotejamento, para a cultivar Catuaí, no período de floração e formação de frutos tipo chumbinho, em plantas com três anos de idade, e encontraram valores de Kc de 1,0 e 1,3. Esses valores são corroborados pelo presente trabalho, pois os maiores valores de Kc foram encontrados no verão (Tabela 1).

Em dois manejos de irrigação para a cultivar IPR59, na região de Londrina, PR, Flumignan \& Faria (2009), utilizaram lisímetros de pesagem e determinaram Kc médio igual a 0,99 e 1,03 no tratamento irrigado por aspersão, no primeiro e segundo anos, respectivamente, e 0,92 para o tratamento irrigado por gotejamento, no segundo ano de cultivo. Esses dados diferem pouco dos encontrados no presente trabalho.

No presente trabalho, os valores de Kc para ETo menor e maior ou igual a $3 \mathrm{~mm}$ por dia foram, respectivamente, de 1,03 e 0,96, para cafeeiros irrigados por aspersão e de 0,97 e 0,81 , para cafeeiros irrigados por gotejamento. Esses dados concordam com as recomendações de Kc de Flumignan et al. (2011), para cafeeiros aos três e quatro anos de idade, com exceção do valor das plantas irrigadas por aspersão em condições de ETo inferior a $3 \mathrm{~mm}$ por dia $(1,28)$. Essa diferença pode estar associada à evaporação do solo, pois, no trabalho de Flumignan et al. (2011), as plantas eram mais jovens e, assim, podem ter apresentado uma importante contribuição dessa componente no computo total da ET.

Estreita relação foi encontrada entre Kc e IAF de cafeeiros, pela regressão linear (Figura 4). Os coeficientes de determinação para ambos os tratamentos irrigados, indicam influência da área foliar em $63 \%$ para aspersão e $55 \%$ para gotejamento no Kc. As retas de regressão indicam, ainda, que o valor de intercepto é similar entre os tratamentos $(0,649$ e 0,625$)$; porém, a declividade

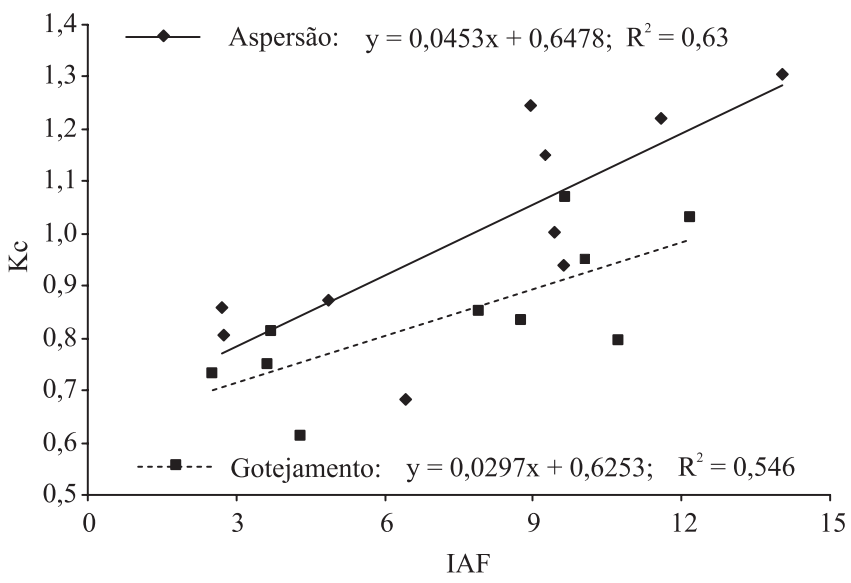

Figura 4. Relação entre índice de área foliar (IAF) e coeficiente de cultivo $(\mathrm{Kc})$ dos cafeeiros irrigados por aspersão e gotejamento, em 2006-2008.

é maior no tratamento sob aspersão $(0,045)$, em comparação ao irrigado por gotejamento $(0,03)$. Esse resultado mostra que o acréscimo em IAF resulta em maior incremento da ET, na irrigação por aspersão do que no gotejamento.

\section{Conclusões}

1. O consumo hídrico do cafeeiro varia em consequência da demanda evaporativa da atmosfera, do método de irrigação e do índice de área foliar.

2. Os valores de evapotranspiração e coeficiente de cultivo são mais elevados no cafeeiro irrigado por aspersão que nos irrigado sob gotejamento e não irrigado.

\section{Referências}

ALLEN, R.G. A Penman for all seasons. Journal of Irrigation and Drainage Engineering, v.12, p.348-368, 1986.

ALLEN, R.G.; PEREIRA, L.S.; RAES, D.; SMITH, M. Crop evapotranspiration: guidelines for computing crop water requirements. Rome: FAO. 1998. 300p. (FAO. FAO irrigation and drainage paper, 56).

BERNARDO, S.; SOARES, A.A.; MANTOVANI, E.C. Manual de irrigação. 7.ed. Viçosa: Universidade Federal de Viçosa, 2005. $611 \mathrm{p}$.

CAMARGO, A.P. de; CAMARGO, M.B.P. de. Definição e esquematização das fases fenológicas do cafeeiro arábica nas condições tropicais do Brasil. Bragantia, v.60, p.65-68, 2001.

CARVALHO, D.F.; SILVA, L.D.B.; GUERRA, J.G.M.; CRUZ, F.A.; SOUZA, A.P. Instalação, calibração e funcionamento de um 
lisímetro de pesagem. Engenharia Agrícola, v.27, p.363-372, 2007.

DOORENBOS, J.; KASSAM, A.H. Yield response to water. Rome: FAO, 1979. 193p. (FAO. FAO irrigation and drainage paper, 33).

FARIA, R.T. de; CAMPECHE, L.F. de S.M.; CHIBANA, E.Y. Construção e calibração de lisímetros de alta precisão. Revista Brasileira de Engenharia Agrícola e Ambiental, v.10, p.237-242, 2006.

FARIA, R.T. de; CARAMORI, P.H. Caracterização fisico-hídrica de um Latossolo Roxo distrófico do Município de Londrina, PR. Pesquisa Agropecuária Brasileira, v.21, p.1303-1311, 1986.

FARIA, R.T. de; CARAMORI, P.H.; CHIBANA, E.Y.; BRITO, L.R. de S.; NAKAMURA, A.K.; FERREIRA, A.R. CLIMA - programa computacional para organização e análise de dados meteorológicos. Londrina: Iapar, 2002. 29p. (IAPAR. Boletim técnico, 66).

FLOSS, E.L. Fisiologia das plantas cultivadas: o estudo do que está por trás do que se vê. 3.ed. Passo Fundo: Universidade de Passo Fundo, 2006. 751p.

FLUMIGNAN, D.L.; ADAMI, M.; FARIA, R.T. de. Área foliar de folhas íntegras e danificadas de cafeeiro determinada por dimensões foliares e imagem digital. Coffee Science, v.3, p.1-6, 2008.

FLUMIGNAN, D.L.; FARIA, R.T. de. Evapotranspiração e coeficientes de cultivo de cafeeiros em fase de formação. Bragantia, v.68, p.269-278, 2009.

FLUMIGNAN, D.L.; FARIA, R.T. de; PRETE, C.E.C. Evapotranspiration components and dual crop coefficients of coffee trees during crop production. Agricultural Water Management, v.98, p.791-800, 2011.

GOMES, A.A.; ARAÚJO, A.P.; ROSSIELLO, R.O.P.; PIMENTEL, C. Acumulação de biomassa, características fisiológicas e rendimento de grãos em cultivares de feijoeiro irrigado e sob sequeiro. Pesquisa Agropecuária Brasileira, v.35, p.1927-1937, 2000.
HOWELL, T.A.; MCCORMICK, R.L.; PHENE, C.J. Design and installation of large weighing lysimeters. Transactions of the American Society of Agricultural Engineers, v.28, p.106-117, 1985.

IAPAR. Agrometeorologia: médias históricas. Disponível em: $<$ http://www.iapar.br/arquivos/Image/monitoramento/Medias Historicas/Londrina.htm>. Acesso em: 2 abr. 2009.

LASCANO, R.J.; SOJKA, R.E. Irrigation of agricultural crops. $2^{\text {nd }}$ ed. Madison: American Society of Agronomy, 2007. 664p. (ASA. Agronomy monograph, 30).

OLIVEIRA, L.F.C. de; OLIVEIRA, R.Z.; BORGES, L.B.; WEHR, T.R.; BONOMO, R. Coeficiente de cultura e relações hídricas do cafeeiro, cultivar Catucaí, sob dois sistemas de manejo da irrigação. Pesquisa Agropecuária Tropical, v.37, p.154-162, 2007.

OLIVEIRA, P.M. de; SILVA, A.M. da; CASTRO NETO, P. Estimativa da evapotranspiração e do coeficiente de cultura do cafeeiro (Coffea arabica L.). Irriga, v.8, p.273-282, 2003.

SANTOS, H.G. dos; JACOMINE, P.K.T.; ANJOS, L.H.C. dos; OLIVEIRA, V.A. de; OLIVEIRA, J.B. de; COELHO, M.R.; LUMBRERAS, J.F.; CUNHA, T.J.F. (Ed.). Sistema brasileiro de classificação de solos. 2.ed. Rio de Janeiro: Embrapa Solos, 2006. $306 \mathrm{p}$.

SATO, F.A.; SILVA, A.M. da; COELHO, G.; SILVA, A.C. da; CARVAlHO, L.G. de. Coeficiente de cultura $(\mathrm{Kc})$ do cafeeiro (Coffea arabica L.) no período de outono-inverno na região de Lavras - MG. Engenharia Agrícola, v.27, p.383-391, 2007.

SMITH, M.; SEGEREN, A.; SANTOS PEREIRA, L.; PERRIER, A.; ALLEN, R. Report on the expert consultation on procedures for revision of FAO guidelines for prediction of crop water requirements. Rome: FAO, 1991. 45p.

VILLA NOVA, N.A.; FAVARIN, J.L.; ANGELOCCI, L.R.; DOURADO-NETO, D. Estimativa do coeficiente de cultura do cafeeiro em função de variáveis climatológicas e fitotéctinas. Bragantia, v.61, p.81-88, 2002.

Recebido em 1 de março de 2010 e aprovado em 8 de agosto de 2011 